\title{
Genetic and epidemiological risk factors in the development of bronchopulmonary dysplasia
}

\author{
Beena Mailaparambil ${ }^{1}$, Marcus Krueger ${ }^{1}$, Ulrike Heizmann, Katharina Schlegel, Jessica Heinze and \\ Andrea Heinzmann* \\ Centre for Pediatrics and Adolescent Medicine, University of Freiburg, Freiburg, Germany
}

\begin{abstract}
Bronchopulmonary dysplasia (BPD) is the chronic lung disease of preterm infants and still represents a major burden of prematurity. Several clinical risk factors for the onset of the disease are already known. In addition, some candidate genes have recently been identified. We set out to determine clinical as well as genetic risk factors for the development of BPD in the German population.

155 infants born with a gestational age $\leqslant 28$ at the tertiary neonatal Centre, Freiburg, were recruited. Clinical data were recorded from hospital charts. 47 children developed moderate or severe BPD. For genetic analyses, 37 polymorphisms within sixteen genes were genotyped on all children.

The strongest epidemiological risk factor for BPD was birth weight, followed by low gestational age. Genetic association was detected with single polymorphisms within Tumour necrosis factor alpha, Toll like receptor 10 and vascular endothelial growth factor. The former two genes showed also association with BPD in haplotype analyses.

In conclusion, association of BPD was far more convincingly found with a few clinical factors than with genetic polymorphisms. This underscores the genetic complexity of the disease. Furthermore, the identification of predisposing genetic polymorphisms might be hampered by the complex interaction between clinical and genetic factors.
\end{abstract}

Keywords: Association, bronchopulmonary dysplasia, genetic, polymorphism

\section{Introduction}

Bronchopulmonary dysplasia (BPD) is the chronic lung disease of premature infants; it affects about 20$30 \%$ of children born at a gestational age of less than 30 weeks. The disease is primarily characterised by a prolonged need of oxygen supplementation. However, affected children are also more likely to develop sequels like language delay, cerebral palsy, and cognitive impairments [1]. Thus BPD is still the leading cause of morbidity and mortality among premature infants $[2$, $3]$.

\footnotetext{
${ }^{1}$ These two authors contributed equally to this work.

${ }^{*}$ Corresponding author: Dr. Andrea Heinzmann, Centre for Pediatrics and Adolescent Medicine, Mathildenstr. 1, D-79106 Freiburg, Germany. Tel.: +49 761 2706371; Fax: +49 761 2706372; E-mail: andrea.heinzmann@uniklinik-freiburg.de.
}

BPD was first described and characterised by Northway et al. in 1967 [4]. Since then, a variety of different definitions have been published and used in clinical practice. Most widely applied was the definition of the NIH workshop on BPD in 1979, which postulated at least 28 days of supplemental oxygen in addition to radiographic changes [5]. Lately, improved therapeutically options - especially advanced technology for mechanical ventilation - and the survival of even smaller infants have changed the clinical appearance of BPD. This led to the advent and classification of the so-called "new BPD" [6]: Now oxygen supplementation for at least 28 days and at 36 weeks postmenstrual age as well as the need of positive airway pressure categorize the severity of the disease in mild, moderate and severe [7, 8].

At least two important pathophysiological pathways exist in the development of the new BPD: First, inflam- 
matory processes that lead to an impairment of alveolarization and vasculogenesis and secondly, growth arrest of the lungs $[9,10]$. The primary event might already occur in utero by inflammation due to chorioamnionitis or immediately postnatal by lung injury due to respiratory distress syndrome and its treatment by mechanical ventilation. The persistence of this inflammation mediated by influx of neutrophils and macrophages in the airways followed by production of reactive oxygen species - finally contributes to impaired lung development, ultimately resulting in BPD [11].

It has been hypothesised already years ago, that in addition to clinical factors a genetic predisposition might determine the development of BPD [12,13]. This hypothesis is supported by recent twin studies, suggesting that genetic factors contribute as much as $53 \%$ to the total risk for the disease [13,14].

Therefore we were interested to identify risk factors for the development of BPD in the German population taking into account both - clinical and genetic - factors. Besides recording and analysing clinical characteristics of the study population, we genotyped 37 polymorphisms within sixteen candidate genes for BPD: These are genes for the airway mucosal response like surfactant protein $\mathrm{C}$ and surfactant protein D (SFPC and SFPD); different growth factors involved in lung remodelling: transforming growth factor (TGF) alpha and beta, connective tissue growth factor (CTGF) and vascular endothelial growth factor (VEGF). Extracellular matrix and adhesion -molecules (such as metalloproteinases) have already been analyzed for their involvement in BPD [15]. Therefore we included in our analysis selectin E (SELE) and intercellular adhesion molecule (ICAM-1) as our study group analyzed these factors previously in other pediatric diseases [16-18]. Finally genes involved in inflammation and innate immune response: Interleukin (IL-)-13, IL-4, IL-8, IL10, IL-18, tumour necrosis factor (TNF) alpha and beta and toll like receptor (TLR-) 10 were analyzed. The selection of SNPs was based on previous studies of the genes by others as well as by us [19].

\section{Material and methods}

\subsection{Subjects}

Preterm infants (gestational age $\leqslant 28$ ) born between January 1996 and August 2007 at the Centre for Pediatrics and Adolescent Medicine, University Hospital Freiburg, Germany, were included: Infants were re- cruited prospectively during their stay on NICU since January 2005. Children born before that time were recruited retrospectively by contacting the parents by mail.

DNA collection was performed either by buccal swabs (majority of cases) or by blood drawing in case of routine blood sampling. Children with chromosomal aberrations, congenital heart defects or other major congenital malformations were excluded from the study. All probands were genetically independent, i.e. no twins or siblings were included. Furthermore, only Caucasian children were recruited for the study to guarantee a homogenous ethnic background of the study population.

Medical charts of the infants were reviewed and clinical data recorded. This included among others the following parameters: Sex, birth weight, gestational age, number of days with supplemental oxygen, need of mechanical ventilation and positive airway pressure, patent ductus arteriosus (as confirmed echographically) and mode of closure (i.e. pharmaceutical or surgical), chorioamnionitis according to placenta histology (hematoxylin and eosin stain), sign of early onset neonatal infection (like elevated $\mathrm{C}$ reactive protein and/or IL-6 in cord blood), need of surfactant therapy and courses of prenatal steroids. At our NICU the following approach is applied regarding the treatment with surfactant: Avoiding of intubation independent of the gestational age. Therefore, even very premature infants are only intubated if they show failure of ventilation and/or need of supplemental oxygen above $40 \%$. Once they required intubation during the immediate postnatal period, they receive surfactant within 2 hours. This practice was consistent during the whole study period.

The BPD definition by Jobe and Bancalari [6] was used to subdivide the infants in two groups. Group 1 included all infants with no or only mild BPD, corresponding to oxygen supplementation for at least 28 days, but no need of supplemental oxygen or positive pressure at 36 weeks of gestational age. Group 2 consists of all infants with moderate and severe BPD (BPD grade two and three according to the original definition), i.e. supplemental oxygen for at least 28 days plus need of oxygen and/or positive pressure at 36 weeks of gestational age. This classification is based on the recent analyses by Lavoie et al. about the heritability of BPD as defined according to the consensus statement of the national institutes of health [20].

\subsection{Genotyping}

DNA was extracted by standard procedures from peripheral blood leucocytes and column purified (DNA 
Table 1

RFLP analyses

\begin{tabular}{|c|c|c|c|c|}
\hline Gene & SNP & Primers & PCR condition & Restriction enzyme \\
\hline \multirow[t]{3}{*}{$\mathrm{TNF} \alpha$} & rs1799964 & $\begin{array}{l}\text { 5', GGGGAGAACAAAAGGATAAG 3' } \\
\text { 5' CCCCATACTCGACTTTCATA 3, }\end{array}$ & $55^{\circ} \mathrm{C}, 40$ cycles & MaeIII \\
\hline & rs 1799724 & $\begin{array}{l}\text { 5', GTATGGGGACCCCCCCGTAA 3', } \\
\text { 5' GACCCGGAGACTCATAATGC 3' }\end{array}$ & $65^{\circ} \mathrm{C}, 35$ cycles & MaeIII \\
\hline & rs 1800629 & 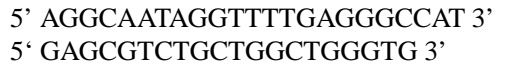 & $55^{\circ} \mathrm{C}, 40$ cycles & Ncol \\
\hline $\mathrm{TNF} \beta$ & rs909253 & $\begin{array}{l}\text { 5' CCGTGCTTCGTGCTTTGGACTA 3, } \\
\text { 5' AGAGCTGGTGGGGACATGTCTG 3, }\end{array}$ & $69^{\circ} \mathrm{C}, 35$ cycles & NcoI \\
\hline \multirow[t]{3}{*}{ VEGF } & rs699947 & $\begin{array}{l}\text { 5, AACCTAGCACCTCCACCAAA 3, } \\
\text { 5, GAACAAAGTTGGGGCTCTGA } 3 \text {, }\end{array}$ & $56^{\circ} \mathrm{C}, 35$ cycles & $\mathrm{BgIII}$ \\
\hline & rs2010963 & $\begin{array}{l}\text { 5, GCCATTCCCCACTTGAAT 3, } \\
\text { 5, GTCACTCACTTTGCCCCTGT 3, }\end{array}$ & $56^{\circ} \mathrm{C}, 35$ cycles & HypF10VI \\
\hline & rs 3025039 & $\begin{array}{l}\text { 5', ACACCATCACCATCGACAGA } 3 \\
\text { 5, GCTCGGTGATTTAGCAGCA 3' }\end{array}$ & $56^{\circ} \mathrm{C}, 35$ cycles & Hin1II \\
\hline \multirow[t]{3}{*}{ TLR-10 } & rs4274855 & $\begin{array}{l}\text { 5' TCCTGACTTACCTCAACAcC 3' } \\
\text { 5' AAGTCTGCGGGAACCTTTCT 3, }\end{array}$ & $59^{\circ} \mathrm{C}, 35$ cycles & MspI \\
\hline & rs11096955 & $\begin{array}{l}\text { 5'GGTAAGGCTTATCTTGACCACA3', } \\
5^{\prime} \text { 'GACGAGTTGTTTAAAAGGACT } 3 \text { ' }\end{array}$ & $54^{\circ} \mathrm{C}, 35$ cycles & Hifn I \\
\hline & rs 10856839 & $\begin{array}{l}\text { 5'CATCATTCATATGAGGAATT 3' } \\
5^{\prime} \text { 'AAGTCTGCGGGAACCTTTCT } 3 \text {, }\end{array}$ & $52^{\circ} \mathrm{C}, 40$ cycles & MseI \\
\hline
\end{tabular}

Primers, PCR condition and restriction enzymes for performing RFLP. Shown is the condition for all SNPs in genes with significant results.

Table 2

Some characteristics of the study population

\begin{tabular}{lcc}
\hline & No BPD/mild BPD $(n=108)$ & Moderate/severe BPD $(n=47)$ \\
\hline Gestational week $^{*}$ & $26(23-28)$ & $25(23-28)$ \\
Sex (proportion males) & 0.454 & 0.532 \\
Birth weight [g] & $905(450-1500)$ & $690(350-1020)$ \\
Prenatal steroids & & $10(21.2 \%)$ \\
$\quad-$ incomplete & $14(13.0 \%)$ & $34(72.3 \%)$ \\
$\quad$ - complete & $85(78.7 \%)$ & $33(70.2 \%)$ \\
Surfactant therapy & $41(38 \%)$ & $20(42.5 \%)$ \\
Chorioamnionitis & $48(44.4 \%)$ & $14(29.8 \%)$ \\
PDA, closure by & $32(29.6 \%)$ & $13(27.7 \%)$ \\
$\quad-$ pharmacological & $5(4.6 \%)$ & \\
$\quad$ - surgical intervention & & \\
\hline
\end{tabular}

This table shows some clinical characteristics of the two groups of preterm infants. ${ }^{*}$ median and range.

midikit, Qiagen, Hildesheim, Germany). In case of buccal swabs the GenomiPhi V2 DNA amplification kit (GE Healthcare, Munich, Germany) was used.

Genotyping was performed by restriction fragment length polymorphism (RFLP) as described previously [19]. The conditions for RFLP analyses for all SNPs within genes showing significant results - i.e. TNF alpha and beta, VEGF and TLR10 - are shown in Table 1.

\subsection{Sequencing}

In order to check the accuracy of RFLP analyses, for each polymorphism three controls (homozy- gous wildtype, heterozygous and homozygous mutation) were sequenced by the dideoxy chain termination method [21] using the Big Dye Terminator cycle sequencing kit on an ABI 310 sequencer (Applied Biosystems). All subsequent RFLP analyses included these reference individuals.

\subsection{Statistical analysis}

Clinical data were analysed by using the SPSS 11.0 package (SPSS Inc., Chicago, Illinois, USA). Genotyping data were analysed for possible association with BPD by using the Armitage's trend 
test for each single polymorphism. This test follows the guidelines given by Sasieni [22] and is implemented in the program Finetti (Thomas F. Wienker, unpublished data; http://ihg.gsf.de/cgi-bin/hw/hwa1.pl and http://ihg.gsf.de/linkage/download/finetti.zip). The same program was used to calculate Hardy Weinberg equilibrium (HWE) for each polymorphism in both populations. A significant deviation from HWE could be a hint to population admixture or genotyping errors [23]. In addition, we performed haplotype frequency estimations and association analyses with FAMHAP [24].

\subsection{Approval}

The collection of blood/buccal swabs and the experimental procedures were approved by the Ethical Committee of the University of Freiburg. Parents were given written and verbal information about the study and a statement of informed consent was signed by the parents of all enrolled children.

\section{Results}

\subsection{Clinical characteristics - epidemiological risk factors}

Initially all infants born at a gestational age $\leqslant 32$ were recruited for our study. However, as BPD was diagnosed only 3 times in 60 infants born between a gestational age of 29 and 32 weeks, these children were eventually excluded from further analyses. Thus 155 children born $\leqslant 28$ weeks of gestational age were included and divided in two groups: 108 infants were assigned to group 1 (no or only mild BPD); 47 infants met inclusion criteria for group 2 (moderate or severe BPD). Some baseline characteristics of both groups are shown in Table 2.

The following major clinical risk factors for BPD were present in our population: Low birth weight was associated with BPD with a chi ${ }^{2}$ of 49.6 ( $p<$ 0.000001 by Kruskal-Wallis-Test) and low gestational age with chi ${ }^{2}=40.0(p<0.000001$ by Kruskal-WallisTest). In addition, length of mechanical ventilation was very strongly associated with the development of BPD ( chi $^{2}=61.1, p<0.000001$ by Kruskal-Wallis-Test). The relationship of low birth weight and length of mechanical ventilation with BPD severity is illustrated in Fig. 1a and b.
Table 3

Polymorphisms under investigation

\begin{tabular}{|c|c|c|c|}
\hline Gene & Polymorphism & Alleles & Position \\
\hline \multirow[t]{2}{*}{ IL-8 } & rs 4073 & $\mathrm{~A} / \mathrm{T}$ & Promoter \\
\hline & rs227306 & $\mathrm{C} / \mathrm{T}$ & Intron \\
\hline \multirow[t]{2}{*}{ SFTPC } & rs8192341 & $\mathrm{A} / \mathrm{C}$ & $\mathrm{T} 138 \mathrm{~N}$ \\
\hline & rs 1124 & $\mathrm{~A} / \mathrm{G}$ & S186N \\
\hline \multirow[t]{2}{*}{ SFTPD } & rs 3088308 & $\mathrm{~A} / \mathrm{T}$ & $\mathrm{S} 290 \mathrm{~T}$ \\
\hline & rs721917 & $\mathrm{C} / \mathrm{T}$ & M31T \\
\hline \multirow[t]{3}{*}{$\mathrm{TNF} \alpha$} & rs 1799964 & $\mathrm{C} / \mathrm{T}$ & 5' UTR \\
\hline & rs 1799724 & $\mathrm{C} / \mathrm{T}$ & 5' UTR \\
\hline & rs 1800629 & $\mathrm{~A} / \mathrm{G}$ & Promoter \\
\hline $\mathrm{TNF} \beta$ & rs909253 & $\mathrm{C} / \mathrm{T}$ & Intron \\
\hline IL-4 & rs 2243250 & $\mathrm{C} / \mathrm{T}$ & Promoter \\
\hline \multirow[t]{3}{*}{ IL-13 } & rs 1881457 & $\mathrm{~A} / \mathrm{C}$ & Promoter \\
\hline & rs 1800925 & $\mathrm{C} / \mathrm{T}$ & Promoter \\
\hline & rs20541 & $\mathrm{C} / \mathrm{T}$ & Q144R \\
\hline \multirow[t]{3}{*}{ VEGF } & rs699947 & $\mathrm{A} / \mathrm{C}$ & Promoter \\
\hline & rs 2010963 & $\mathrm{C} / \mathrm{G}$ & 5' UTR \\
\hline & rs 3025039 & $\mathrm{C} / \mathrm{T}$ & 3' UTR \\
\hline \multirow[t]{2}{*}{ TGF $\beta$} & rs 1800471 & $\mathrm{C} / \mathrm{G}$ & 5' UTR \\
\hline & rs 1800469 & $\mathrm{C} / \mathrm{T}$ & 5' UTR \\
\hline TGF $\alpha$ & rs 2166975 & $\mathrm{~A} / \mathrm{G}$ & V160V \\
\hline \multirow[t]{2}{*}{ IL-10 } & rs 3024498 & $\mathrm{~A} / \mathrm{G}$ & 3' UTR \\
\hline & rs 1800872 & $\mathrm{~A} / \mathrm{C}$ & Promoter \\
\hline \multirow[t]{2}{*}{ SELE } & rs5368 & $\mathrm{C} / \mathrm{T}$ & H468Y \\
\hline & rs5361 & $\mathrm{A} / \mathrm{C}$ & S149R \\
\hline \multirow[t]{2}{*}{ CTGF } & rs9399005 & $\mathrm{C} / \mathrm{T}$ & 5' UTR \\
\hline & rs6918698 & $\mathrm{C} / \mathrm{G}$ & Promoter \\
\hline \multirow[t]{2}{*}{ ICAM } & rs5498 & $\mathrm{A} / \mathrm{G}$ & Promoter \\
\hline & rs885743 & $\mathrm{A} / \mathrm{T}$ & Intron \\
\hline \multirow[t]{6}{*}{ IL-18 } & rs 1946518 & $\mathrm{G} / \mathrm{T}$ & Promotor \\
\hline & rs 187238 & $\mathrm{C} / \mathrm{G}$ & Promotor \\
\hline & rs360718 & $\mathrm{A} / \mathrm{C}$ & Exon \\
\hline & rs360717 & $\mathrm{C} / \mathrm{T}$ & Exon \\
\hline & rs795467 & $\mathrm{A} / \mathrm{G}$ & Intron \\
\hline & rs360721 & $\mathrm{C} / \mathrm{G}$ & Intron \\
\hline \multirow[t]{3}{*}{ TLR10 } & rs4274855 & $\mathrm{C} / \mathrm{T}$ & Promotor \\
\hline & rs11096955 & $\mathrm{A} / \mathrm{C}$ & I369L \\
\hline & rs10856839 & $\mathrm{A} / \mathrm{C}$ & 5' UTR \\
\hline
\end{tabular}

SNPs under investigation and their position within the genes. The corresponding nucleotide substitution is shown as well as the amino acid exchange where applicable.

BPD was more often seen in infants who had a patent ductus arteriosus (PDA) with need of either pharmaceutical or surgical therapy. Highest incidence of BPD was seen in infants undergoing surgical ligature of PDA $(p<0.0001$, Kruskal-Wallis-Test). Finally, boys were not more often affected than girls in our study ( $p=$ 0,419 by Kruskal-Wallis-Test).

\subsection{Association analyses - genetic risk factors}

155 infants were genotyped for 37 single nucleotide polymorphisms (SNPs) within 16 genes. The genes and SNPs under investigation are listed in Table 3. The genotyping data, the results of HWE calculation and p-values for association with BPD as calculated by the Armitage's Trend test are shown in Table 4. 
A

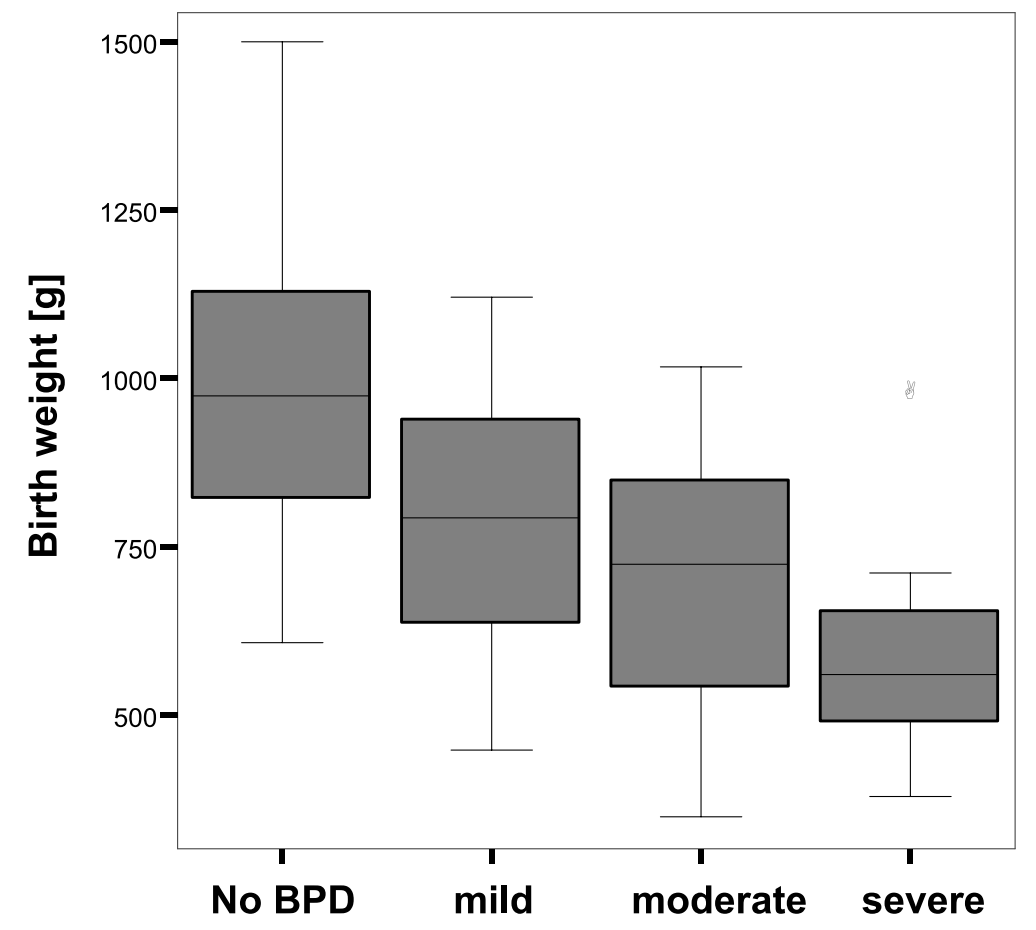

B
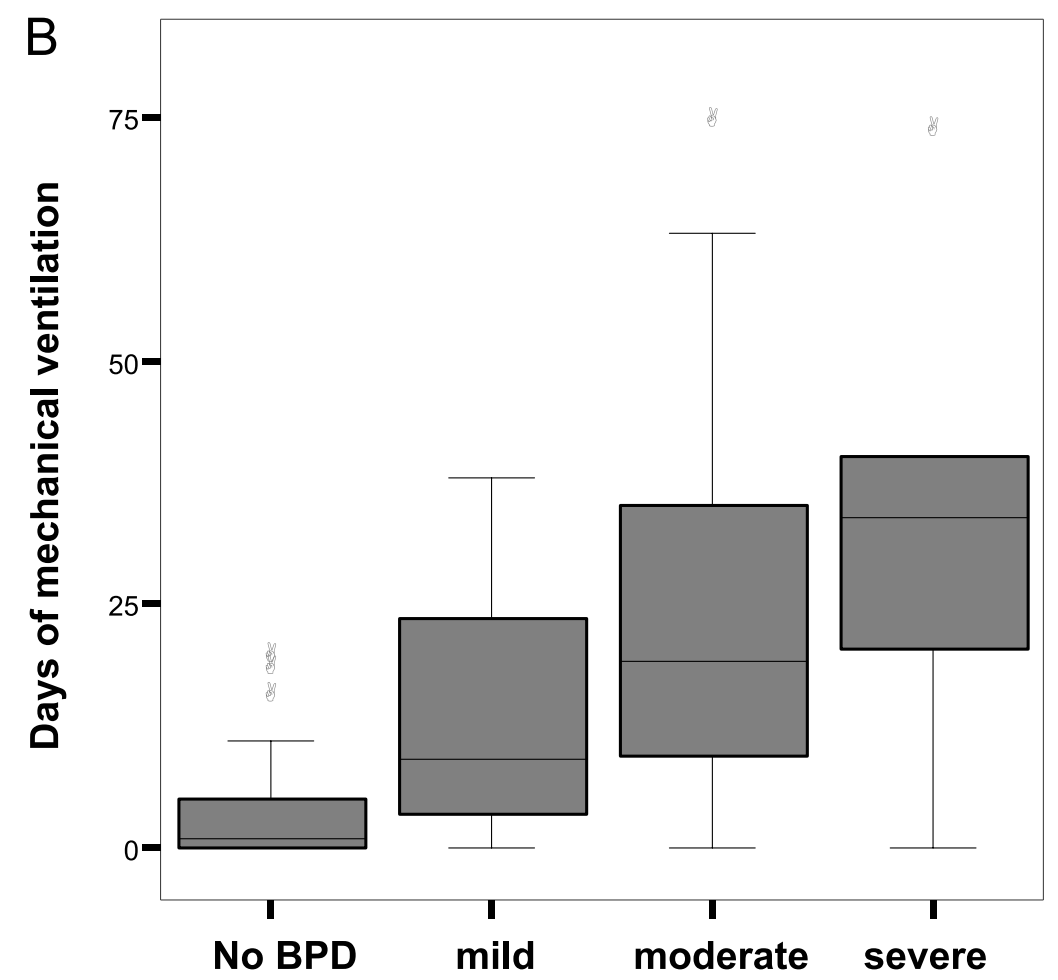

Fig. 1. BPD severity as defined by Banclarari et al. [6]. Shown are the median and the $95 \%$ confidence interval. Small circles represent outlier. a) According to birth weight. b) According to days of mechanical ventilation. 
Table 4

Results of association analyses

\begin{tabular}{|c|c|c|c|c|c|c|}
\hline Gene & Polymorphism & Genotypes BPD & HWE BPD & Genotypes controls & HWE controls & $p$ value for association \\
\hline \multirow[t]{2}{*}{ IL-8 } & rs227306 & $11,28,7$ & 0.124 & $27,57,22$ & 0.423 & 0.7333 \\
\hline & rs 4073 & $8,30,7$ & 0.025 & $22,60,25$ & 0.206 & 0.6578 \\
\hline \multirow[t]{2}{*}{ SPC } & rs8192341 & $24,17,4$ & 0.714 & $60,37,8$ & 0.498 & 0.6560 \\
\hline & rs1124 & $18,26,2$ & 0.092 & $47,48,9$ & 0.506 & 0.8717 \\
\hline \multirow[t]{2}{*}{ SPD } & rs721917 & $20,16,10$ & 0.067 & $32,57,17$ & 0.316 & 0.5404 \\
\hline & rs 3088308 & $40,5,1$ & 0.218 & $90,14,3$ & 0.044 & 0.6576 \\
\hline \multirow[t]{3}{*}{$\mathrm{TNF} \alpha$} & rs1799724 & $33,6,5$ & 0.002 & $93,15,0$ & 1.000 & 0.0085 \\
\hline & rs1799964 & $25,19,0$ & 0.170 & $69,36,2$ & 0.356 & 0.5290 \\
\hline & rs 1800629 & $33,10,1$ & 0.579 & $75,28,4$ & 0.490 & 0.5037 \\
\hline $\mathrm{TNF} \beta$ & rs909253 & $20,19,4$ & 1.000 & $54,40,12$ & 0.281 & 0.8427 \\
\hline Il-4 & rs 2243250 & $33,12,0$ & 1.000 & $83,21,3$ & 0.366 & 0.8665 \\
\hline \multirow[t]{3}{*}{ IL-13 } & rs 1881457 & $25,19,1$ & 0.408 & $70,31,6$ & 0.362 & 0.5292 \\
\hline & rs 1800925 & $30,13,2$ & 0.637 & $71,32,5$ & 0.544 & 0.9130 \\
\hline & rs 20541 & $28,14,1$ & 1.000 & $68,34,4$ & 1.000 & 0.8090 \\
\hline \multirow[t]{3}{*}{ VEGF } & rs 2010963 & $27,15,5$ & 0.258 & $50,43,15$ & 0.252 & 0.2393 \\
\hline & rs699947 & $9,19,18$ & 0.339 & $31,57,19$ & 0.414 & 0.0138 \\
\hline & rs 3025039 & $37,8,1$ & 0.421 & $85,23,0$ & 0.603 & 0.9529 \\
\hline \multirow[t]{2}{*}{ TGF $\beta$} & rs 1800471 & $37,7,0$ & 1.000 & $96,7,2$ & 0.021 & 0.4069 \\
\hline & rs 1800469 & $14,26,5$ & 0.172 & $41,50,17$ & 0.787 & 0.8530 \\
\hline TGF $\alpha$ & rs 2166975 & $26,16,4$ & 0.464 & $57,44,7$ & 0.700 & 0.8896 \\
\hline \multirow[t]{2}{*}{ IL-10 } & rs 1800872 & $23,17,5$ & 0.490 & $61,34,10$ & 0.118 & 0.4725 \\
\hline & rs3024498 & $24,19,2$ & 0.699 & $68,30,8$ & 0.089 & 0.4822 \\
\hline \multirow[t]{2}{*}{ SELE } & rs5361 & $34,12,0$ & 1.000 & $87,20,0$ & 0.594 & 0.3024 \\
\hline & rs5368 & $35,12,0$ & 1.000 & $84,20,4$ & 0.074 & 0.9635 \\
\hline \multirow[t]{2}{*}{ CTGF } & rs6918698 & $10,19,17$ & 0.295 & $39,38,30$ & 0.003 & 0.0906 \\
\hline & rs9399005 & $31,15,0$ & 0.580 & $65,32,10$ & 0.053 & 0.1396 \\
\hline \multirow[t]{2}{*}{ ICAM } & rs885743 & $20,12,8$ & 0.037 & $34,50,18$ & 0.959 & 0.2894 \\
\hline & rs5498 & $23,14,7$ & 0.056 & $41,51,14$ & 0.765 & 0.3829 \\
\hline \multirow[t]{6}{*}{ IL18 } & rs 1946518 & $10,25,9$ & 0.363 & $40,54,13$ & 0.420 & 0.0539 \\
\hline & rs187238 & $23,14,8$ & 0.048 & $60,31,16$ & 0.002 & 0.5557 \\
\hline & rs 360718 & $26,15,3$ & 0.683 & $60,44,3$ & 0.125 & 0.9225 \\
\hline & rs360717 & $25,16,4$ & 0.701 & $59,44,4$ & 0.223 & 0.6548 \\
\hline & rs795467 & $24,17,3$ & 1.000 & $59,42,5$ & 0.470 & 0.7640 \\
\hline & rs 360721 & $31,14,1$ & 1.000 & $73,28,4$ & 0.497 & 0.9585 \\
\hline \multirow[t]{3}{*}{ TLR10 } & rs 10856839 & $27,9,3$ & 0.118 & $74,26,3$ & 0.706 & 0.4771 \\
\hline & rs11096955 & $23,16,5$ & 0.468 & $30,59,18$ & 0.227 & 0.0149 \\
\hline & rs 4274855 & $31,10,3$ & 0.125 & $59,40,8$ & 0.736 & 0,1559 \\
\hline
\end{tabular}

This table summarizes the results of genotyping. Given are the genotype distribution - as numbers of individuals for each genotype in the BPD group (moderate and severe BPD) and controls (i.e. no or mild BPD), the $p$ values for Hardy-Weinberg-Equilibrium (HWE) and the $p$-values for association with BPD.

Association of BPD was detected with three SNPs within three different genes: rs1799724 in TNF-alpha $(p=0.0085)$, rs699947 in VEGF $(p=0.0138)$ and rs11096955 in TLR10 ( $p=0.0149$ ). However, one should bear in mind that by applying Bonferroni correction for all tested SNPs the association does not stay significant.

Furthermore, haplotype analysis was performed by FAMHAP for those genes in which at least two SNPs were genotyped. Genes lying next to each other on the same chromosomes were combined in analyses these are $I L-4$ and $I L-13$ as well as $T N F$-alpha and beta. The results are demonstrated in Table 5. Weak association of BPD was found with haplotypes of TNF alpha/beta $(p=0.0544)$ and TLRIO $(p=0.0273)$.

\section{Discussion}

In this study we sought to identify epidemiological and genetic risk factors for the development of the chronic lung disease of prematurity, bronchopulmonary dysplasia. In our study population, 47 out of 155 infants born at a gestational age of $\leqslant 28$ weeks developed moderate or severe BPD.

The major clinical risk factors for BPD in this population were low birth weight, low gestational age and a long period of mechanical ventilation (see also Fig. 1). In the modern concepts of testing infants of extreme low birth weight exposed to more gentle procedures for mechanical ventilation, the impact of barotrauma and oxygen toxicity has decreased and low birth weight and 
young gestational age have become even more important. Additional strong risk factors for the so-called new BPD include early infection - either prenatal or nosocominal - and a PDA [25]. Accordingly, we found strong association with the mode of PDA closure and BPD. In infants undergoing surgical ligature of PDA the prevalence of BPD was highest. However, it is not possible to decide on the basis of our results whether primarily the ductus arteriosus remains open due to lung disease or whether BPD develops due to persisting ductus and the consecutive blood flooding of the lung. While these risk factors are already known and well described [26,27] nowadays genetic factors come in the focus of interest.

During the last years, a few candidate genes studies have been published in the context of BPD. The inclusion criteria of the study populations varied greatly between different research groups; this might explain some of the conflicting results. For example, some studies used healthy term infants as controls to preterm infants with BPD [28]. The results of such studies might be biased to the identification of genes for prematurity rather than genes for BPD. Others included all preterm infants (i.e. born $\leqslant 36$ weeks of gestational age); as BPD develops only very rarely in infants born at a gestational age $\geqslant 30$ weeks this might also hamper the identification of true association.

To overcome these forms of bias as much as possible we included only children born $\leqslant 28$ weeks of gestational age. This group was divided in BPD affected children and controls according to the definition by Jobe et al. [6]. In addition, only children with need of supplemental oxygen and/or positive airway pressure at a gestational age of 36 weeks were included in the case population, i.e. moderate and severe BPD. This classification was chosen for three reasons: First, the case number of this study population would be too small to subdivide the infants into four groups according to disease severity (no, mild, moderate, severe BPD). Secondly, infants with mild BPD were combined to children without BPD as for very premature infants - as represented in our study population - oxygen supplementation for 28 days might rather reflect a normal transiently condition than lung disease. Thus only oxygen supplementation at a gestational age of 36 weeks (or positive airway pressure) qualified for the case population. Thirdly, this classification is supported by a recent study by Lavioe and colleagues [20]: By investigating 318 twin pairs of known zygosity, they identified genetic factors to account for $82 \%$ of the observed variance in BPD susceptibility as defined on the basis of need for supplemental oxygen at 36 weeks of gestational age.
Table 5

Results of haplotype analyses

\begin{tabular}{lc}
\hline Gene & $\mathrm{p}$ \\
\hline Interleukin-8 & 0.2546 \\
Surfactant Protein C & 0.4284 \\
Surfactant Protein D & 0.5605 \\
Tumour necrosis factor alpha and beta & $\mathbf{0 . 0 5 4 4}$ \\
Interleukin-4/-13 & 0.6270 \\
Vascular endothelial growth factor & 0.2521 \\
Transforming growth factor beta & 0.6523 \\
Interleukin-10 & 0.5096 \\
Selectin E & 0.6232 \\
Connective tissue growth factor & 0.2908 \\
Intercellular adhesion molecule 1 & 0.4373 \\
Interleukin-18 & 0.6430 \\
Toll like receptor 10 & $\mathbf{0 . 0 2 7 3}$ \\
\hline
\end{tabular}

This table shows the results of haplotype analyses using the program FAMHAP.

Heritability of BPD is based on different processes influencing the premature lung during its development. The inflammatory process which may already start prenatal is one of the targets for genetic research. It is well know that inflammatory activation of different cell types such as macrophages, lymphocytes or neutrophils trigger the development of BPD. The pathways including activation and control of the lung response to injury is represented in this study by the analysis of polymorphisms in different interleukins and TNF genes. Using this approach, association was identified with polymorphisms of TNF alpha, VEGF and TRL10 and BPD.

TNF-alpha plays a major role in the regulation of inflammation by affecting the release of other proinflammatory cytokines. Polymorphisms may lead to prolonged inflammation and consecutively tissue damage. Exaggerated reparative procedures of the immature lung may as well enhance lung injury such as fibrosis. Association of TNF alpha with BPD has already been described some years ago [29]. However, other failed to replicate these findings [30]; this might be caused by the smaller sample size. Just very recently, association of TNF alpha haplotypes was described with levels of TNF alpha in tracheal aspirate fluids of preterm infants. Furthermore, the authors found association of haplotypes with the occurrence of chorioamnionitis, but not with BPD [31]. In our study population, association of the polymorphism rs1799724 and TNF alpha haplotypes with BPD was only weak and does not hold up Bonferroni correction. Still, the same SNP was found to alter gene expression [32]. Furthermore, we recently demonstrated that this polymorphism is in association with altered serum levels of TNF-alpha in an asthmatic population [33]. Taken to- 
gether with the above mentioned studies genetic variants in TNF alpha may only play a minor (and thus sometimes elusive) role in the genetic predisposition to BPD. Interestingly, this has just been confirmed very recently in a meta-analysis [34].

The involvement of VEGF particularly in the pathophysiology of new BPD was reviewed recently [35]. By the definition of new BPD as arrest of lung development rather than lung injury, genetic factors involved in the development of vessels and bronchial branching came into the focus of genetic analysis. VEGF represent a vital factor in endothelial differentiation and angiogenesis. Absence of VEGF results in impaired formation of the micro-vascular architecture [36,37]. Relevant implications of VEGF polymorphisms were described in different studies, for example altered VEGF serum levels [38,39]. We found association of rs699947 in $V E G F$ with BPD $(p=0.0138)$. Also association of $V E G F$ with BPD has been described in the Polish population just some months ago [40]. Kwinta et al. used different SNPs within VEGF than we used in our own study. Identification of association with different SNPs in $V E G F$ might underscore the importance of this gene in BPD development.

Until now, no data have been published about the role of TLR10 in the pathophysiology of BPD. However, as TLR10 is part of the innate immune response and infections are an important risk factor for BPD an involvement seems reasonable. The association of one single polymorphism was also supported by haplotype association in our population. In addition, TLR10 have already been described in association with other lung diseases like bronchial asthma [41]. However, once again this association is not robust to correction for multiple testing and thus it might be possible, that the association is false positive.

The other thirteen genes under investigation did not show any hint for an involvement in the genetic predisposition to BPD. Even IL-13 and IL-4 as very strong inflammatory cytokines did not show any association. A previous study in Taiwanese children also failed to find association of IL-4 with the disease [42]. SNPs tested in different surfactant proteins were shown to be associated with BPD in the surfactant protein-C and -D genes, although different SNPs were compared between these two studies [43].

However, the case number of our study is still limited and thus some genes might escape significance for association due to a limited statistical power. As prematurity beyond a gestational age of 28 weeks is quite rare, sufficient case numbers and thus statistical pow- er might only be reached by a multi-centre approach. However, combining children born in different clinics may also confer potential bias, as postnatal treatment varies between centres.

We conclude that even using the options of advanced neonatal treatment the established clinical risk factors still show a high impact on the development of BPD. In addition, our results point to an involvement of immune- and angiogenesis-related genes in the genetics of BPD. Still, the candidate genes identified in this single-centre study need confirmation in larger study populations.

\section{Acknowledgements}

We wish to thank all the infants and their families for their willingness to join our study. In addition, we like to express our thanks to the team of the Neonatal intensive care Unit for supporting the study.

\section{References}

[1] M.C. Walsh, S. Szefler, J. Davis, M. Allen, L. Van Marter, S. Abman, L. Blackmon and A. Jobe, Summary proceedings from the bronchopulmonary dysplasia group, Pediatrics 117 (2006), 52-56.

[2] J.P. Kinsella, A. Greenough and S.H. Abman, Bronchopulmonary dysplasia, Lancet 367 (2006), 1421-1431.

[3] G. Bokodi, A. Treszl, L. Kovács, T. Tulassay, B. Vásárhelyi, Dysplasia, a review, Pediatr Pulmonol 42 (2007), 952-961.

[4] W.H. Jr. Northway, R.C. Rosan and D.Y. Porter, Pulmonary disease following respirator therapy of hyaline-membrane disease. Bronchopulmonary dysplasia, N Engl J Med 276 (1967), 357-368.

[5] Report of workshop on Bronchopulmonary dysplasia; NIH publication No. 80-1660. Washington, DC, National Institutes of Health; 1979.

[6] A.H. Jobe, E. Bancalari, Bronchopulmonary displasia, Am J Respir Crit Care Med 163 (2001), 1723-1729.

[7] R.A. Ehrenkranz, M.C. Walsh, B.R. Vohr, A.H. Jobe, L.L. Wright, A.A. Fanaroff, L.A. Wrage and K. Poole, National Institutes of Child Health and Human Development Neonatal Research Network. Validation of the National Institutes of Health consensus definition of bronchopulmonary dysplasia, Pediatrics 116 (2005), 1353-1360.

[8] R.M. Ryan, A new look at bronchopulmonary dysplasia classification, J Perinatol 26 (2006), 207-209.

[9] C.T. D'Angio and W.M. Maniscalco, The role of vascular growth factors in hyperoxia-induced injury to the developing lung, Front Biosci 7 (2002), 1609-1623.

[10] F. Groenman, S. Unger and M. Post, The molecular basis for abnormal human lung development, Biol Neonate 87 (2005), 164-177.

[11] R.M. Ryan, Q. Ahmed and S. Lakshminrusimha, Inflammatory mediators in the immunobiology of bronchopulmonary dysplasia, Clin Rev Allergy Immunol 34 (2008), 174-190. 
[12] L.A. Parton, S.S. Strassberg, D. Qian, P.A. Galvin-Parton and I.A. Cristea, The genetic basis for bronchopulmonary dysplasia, Front Biosci 11 (2006), 1854-1860.

[13] V. Bhandari, M.J. Bizzarro, A. Shetty, X. Zhong, G.P. Page, H. Zhang, L.R. Ment and J.R. Gruen, Neonatal Genetics Study Group.Familial and genetic susceptibility to major neonatal morbidities in preterm twins, Pediatrics 117 (2006), 19011906.

[14] V. Bhandari and J.R. Gruen, The genetics of bronchopulmonary dysplasia, Semin Perinatol 30 (2006), 185-191.

[15] A. Hadchouel, F. Decobert, M.L. Franco-Montoya, I. Halphen, P.H. Jarreau, O. Boucherat, E. Martin, A. Benachi, S. Amselem, J. Bourbon, C. Danan and C. Delacourt, Matrix metalloproteinase gene polymorphisms and bronchopulmonary dysplasia: identification of MMP16 as a new player in lung development PLoS One 3 (2008), e3188.

[16] B. Puthothu, M. Krueger, M. Bernhardt and A. Heinzmann, ICAM1 amino-acid variant $\mathrm{K} 469 \mathrm{E}$ is associated with paediatric bronchial asthma and elevated sICAM1 levels, Genes Immun 7 (2006), 322-326

[17] M. Krueger, A. Heinzmann and M. Nauck, Adhesion molecules in pediatric intensive care patients with organ dysfunction syndrome, Intensive Care Med 33 (2007), 359-363.

[18] C. Pieh, M. Krueger, W.A. Lagreze, C. Gimpel, C. Buschbeck, U. Zirrgiebel and H. Agostini, Plasma sE-selectin in premature infants: A possible surrogate marker of retinopathy of prematurity, Invest Ophthalmol Vis Sci, (2010) Feb 24. [Epub ahead of print] PubMed PMID: 20181841.

[19] A. Heinzmann, B. Mailaparambil, N. Mingurilli and M. Krueger, Association of Interleukin-13/-4 and Toll like receptor 10 with preterm births, Neonatology 96 (2009), 175-181.

[20] P.M. Lavoie, C. Pham and K.L. Jang, Heritability of bronchopulmonary dysplasia, defined according to the consensus statement of the national institutes of health, Pediatrics 122 (2008), 479-485.

[21] F. Sanger, S. Nicklen and A.R. Coulson, DNA sequencing with chain-terminating inhibitors. 1977, Biotechnology 24 (1992), 104-108.

[22] P.D. Sasieni, From genotypes to genes, doubling the sample size, Biometrics 53 (1997), 1253-1261.

[23] J. Xu, A. Turner, J. Little, E.R. Bleecker and D.A. Meyers, Positive results in association studies are associated with departure from Hardy-Weinberg equilibrium, hint for genotyping error? Hum Genet 111 (2002), 573-574.

[24] T. Becker and M. Knapp, Maximum-likelihood estimation of haplotype frequencies in nuclear families, Genet Epidemiol 27 (2004), 21-32.

[25] E. Bancalari, Changes in the pathogenesis and prevention of chronic lung disease of prematurity, Am J Perinatol 18 (2001), $1-9$.

[26] M.A. Rojas, A. Gonzalez, E. Bancalari, N. Claure, C. Poole and G. Silva-Neto, Changing trends in the epidemiology and pathogenesis of neonatal chronic lung disease, J Pediatr 126 (1995), 605-610.

[27] M. Palta, D. Gabbert, M.R. Weinstein and M.E. Peters, Multivariate assessment of traditional risk factors for chronic lung disease in very low birth weight neonates. The Newborn Lung Project, J Pediatr 119 (1991), 285-292.

[28] M.H. Manar, M.R. Brown, T.W. Gauthier and L.A. Brown, Association of glutathione-S-transferase-P1 (GST-P1) polymorphisms with bronchopulmonary dysplasia, J Perinatol $\mathbf{2 4}$ (2004), 30-35.
[29] S.N. Kazzi, U.O. Kim, M.W. Quasney and I. Buhimschi, Polymorphism of tumor necrosis factor-alpha and risk and severity of bronchopulmonary dysplasia among very low birth weight infants, Pediatrics 114 (2004), 243-248.

[30] S.S. Strassberg, I.A. Cristea, D. Qian and L.A. Parton, Single nucleotide polymorphisms of tumor necrosis factor-alpha and the susceptibility to bronchopulmonary dysplasia, Pediatr Pulmonol 42 (2007), 29-36.

[31] S.N. Kazzi, G. Tromp, M.W. Quasney and I.A. Buhimschi, Haplotypes of tumor necrosis factor gene and tracheal aspirate fluid levels of tumor necrosis factor-alpha in preterm infants, Pediatr Res 64 (2008), 165-170.

[32] T. Higuchi, N. Seki, S. Kamizono, A. Yamada, A. Kimura, H. Kato and K. Itoh, Polymorphism of the 5'-flanking region of the human tumor necrosis factor (TNF)-alpha gene in Japanese, Tissue Antigens 51 (1998), 605-612.

[33] B. Puthothu, S. Bierbaum, M.V. Kopp, J. Forster, J. Heinze, M. Weckmann, M. Krueger and A. Heinzmann, Association of TNF-alpha with severe respiratory syncytial virus infection and bronchial asthma, Pediatr Allergy Immunol 20 (2009), 157-163.

[34] M. Chauhan, S. Bombell and W. McGuire, Tumour necrosis factor (-308A) polymorphism in very preterm infants with broncho-pulmonary dysplasia, meta-analysis, Arch Dis Child Fetal Neonatal Ed 94 (2009), 257-259.

[35] B. Thébaud, Angiogenesis in lung development, injury and repair, implications for chronic lung disease of prematurity, Neonatology 91 (2007), 291-297.

[36] T.M. Asikainen, N.S. Waleh, B.K. Schneider, R.I. Clyman and C.W. White, Enhancement of angiogenic effectors through hypoxia-inducible factor in preterm primate lung in vivo, $A m$ J Physiol Lung Cell Mol Physiol 291 (2006), 588-595.

[37] P. Lassus, A. Ristimäki, O. Ylikorkala, L. Viinikka, S. Andersson, Vascular endothelial growth factor in human preterm lung, Am J Respir Crit Care Med 159 (1999), 1429-1433.

[38] C.J. Watson, N.J. Webb, M.J. Bottomley and P.E. Brenchley, Identification of polymorphisms within the vascular endothelial growth factor (VEGF) gene, correlation with variation in VEGF protein production, Cytokine 12 (2002), 1232-1235.

[39] A. Stevens, J. Soden, P.E. Brenchley, S. Ralph, D.W. Ray, Haplotype analysis of the polymorphic human vascular endothelial growth factor gene promoter, Cancer Res 63 (2003), 812-816.

[40] P. Kwinta, M. Bik-Multanowski, Z. Mitkowska, T. Tomasik, M. Legutko and J.J. Pietrzyk, Genetic risk factors of bronchopulmonary dysplasia, Pediatr Res 64 (2008), 682-688.

[41] R. Lazarus, B.A. Raby, C. Lange, E.K. Silverman, D.J. Kwiatkowski, D. Vercelli, W.J. Klimecki, F.D. Martinez and S.T. Weiss, TOLL-like receptor 10 genetic variation is associated with asthma in two independent samples, Am J Respir Crit Care Med 170 (2004), 594-600.

[42] H.C. Lin, B.H. Su, J.S. Chang, C.M. Hsu, C.H. Tsai and F.J. Tsai, No association of interleukin 4 intron 3 and 590 promoter polymorphisms with bronchopulmonary dysplasia for ventilated preterm infants, Biol Neonate 87 (2005), 181186.

[43] J. Pavlovic, C. Papagaroufalis, M. Xanthou, W. Liu, R. Fan, N. J. Thomas, I. Apostolidou, E. Papathoma, E. Megaloyianni, S. DiAngelo and J. Floros, Genetic variants of surfactant proteins A, B, C, and D in bronchopulmonary dysplasia, Dis Markers 22 (2006), 277-291. 


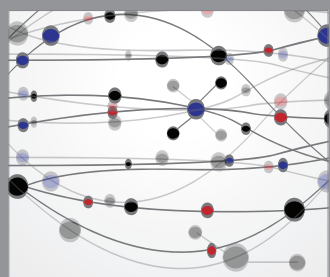

The Scientific World Journal
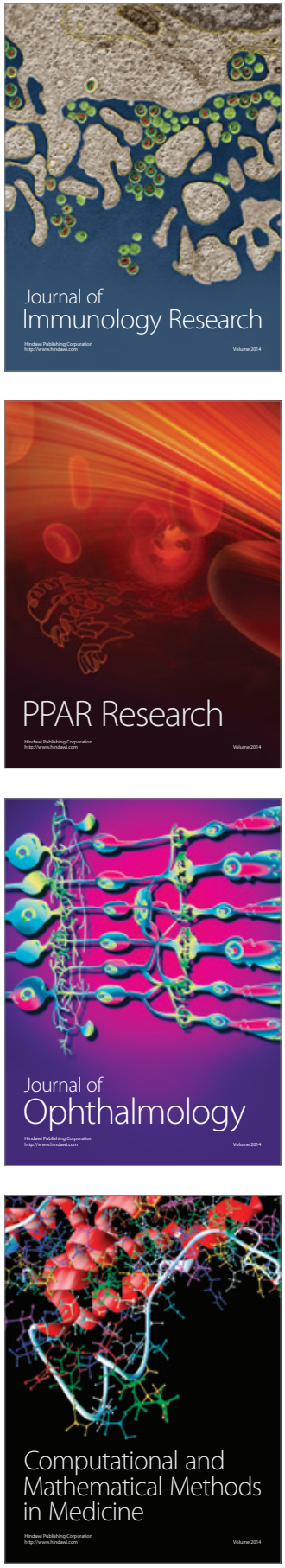

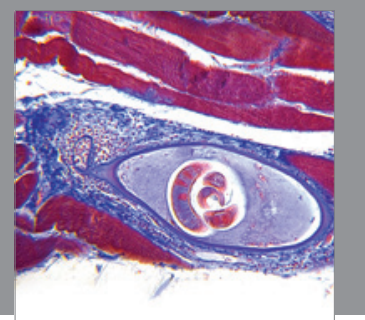

Gastroenterology

Research and Practice
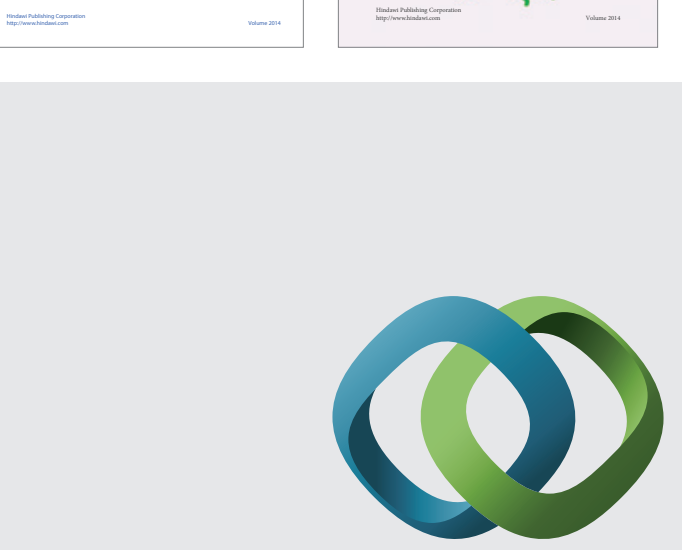

\section{Hindawi}

Submit your manuscripts at

http://www.hindawi.com
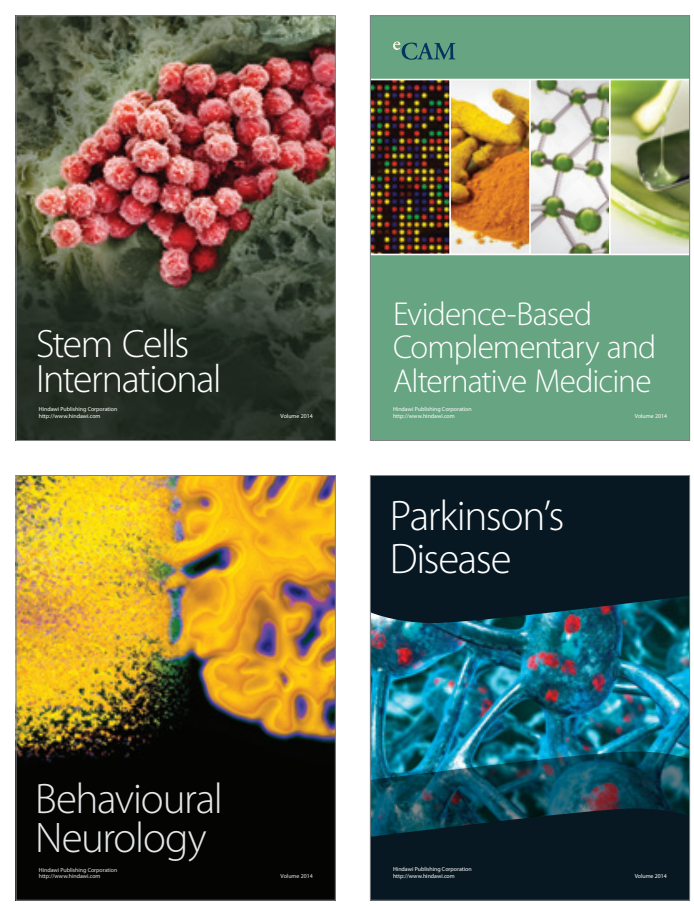

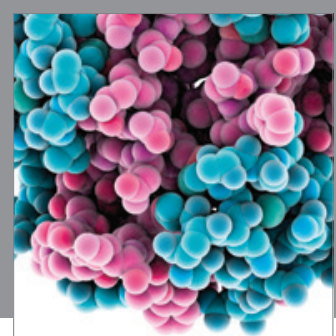

Journal of
Diabetes Research

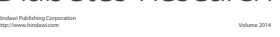

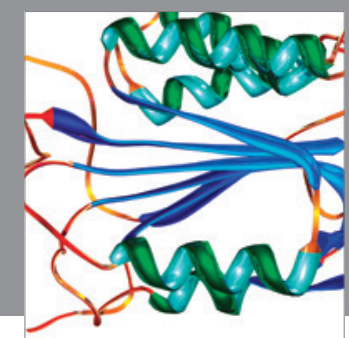

Disease Markers
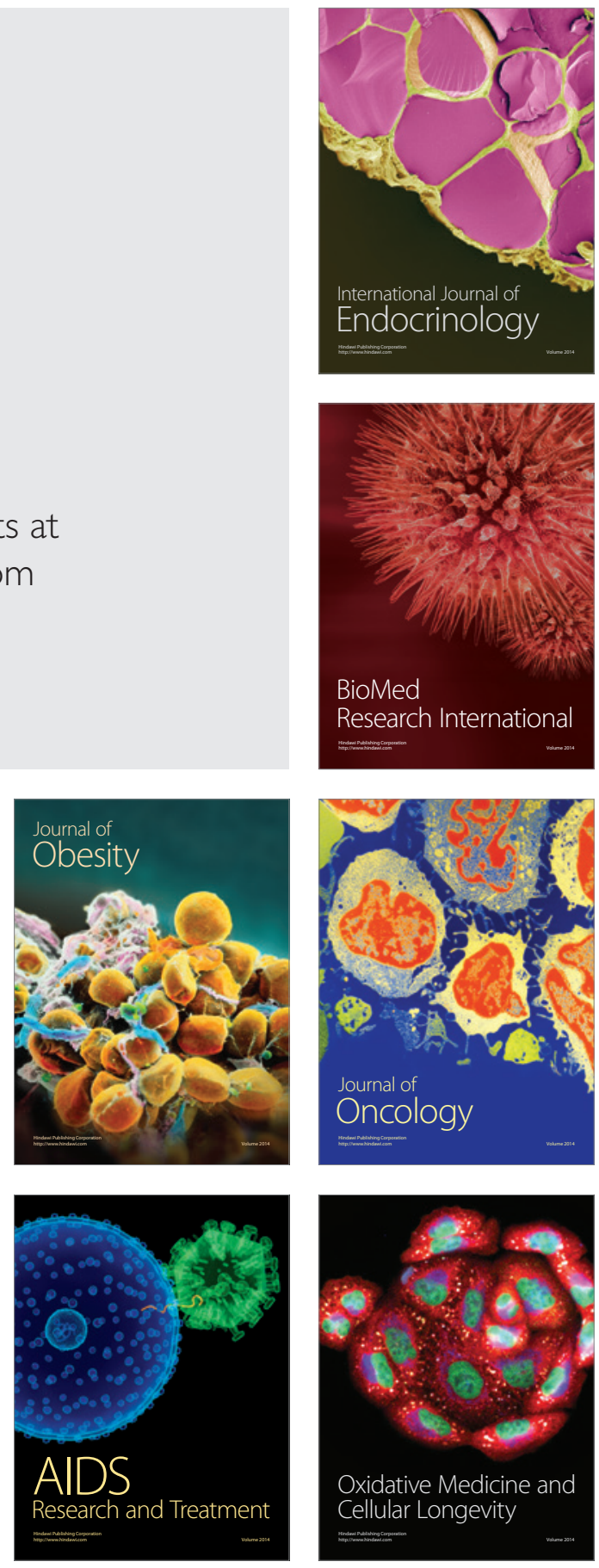